\title{
GLP-2 Suppresses LPS-Induced Inflammation in Macrophages by Inhibiting ERK Phosphorylation and NF- $\mathrm{KB}$ Activation
}

\author{
Shanshan Xie ${ }^{a}$ Bingrun Liu ${ }^{a}$ Shoupeng Fu ${ }^{b}$ Wei Wang ${ }^{b}$ Yunhou Yin ${ }^{c}$ Nan Li ${ }^{a}$ \\ Wei Chen ${ }^{\mathrm{b}}$ Juxiong Liu ${ }^{\mathrm{b}}$ Dianfeng Liu ${ }^{\mathrm{a}}$ \\ ${ }^{a}$ College of Animal Science (Laboratory Animal Center), Jilin University, ${ }^{b}$ College of Veterinary Medicine, \\ Jilin University, Changchun, 'Guizhou Minzu University, Guiyang, P.R. China
}

\author{
Key Words \\ GLP-2 $・$ Pro-inflammatory cytokines $・ E R K ・ N F-K B$
}

\begin{abstract}
Background/Aims: GLP-2 has been shown to exert anti-inflammatory effects, but the underlying molecular mechanisms remained undefined. As macrophages are important in the development and maintenance of inflammation, we investigated whether exogenous GLP-2 modulates the expression of pro-inflammatory proteins in LPS stimulated murine peritoneal macrophages. Methods: Macrophages were pretreated with various concentrations of GLP-2 for $1 \mathrm{~h}$ and then stimulated with LPS. The effects on pro-inflammatory enzymes (iNOS and COX-2), and pro-inflammatory cytokines (TNF- $\alpha$, IL-1 $\beta$ and IL-6) were analysed by Western blotting, ELISA and qRT-PCR. We also examined whether NF-KB or MAPK signaling was involved in the effects of GLP-2. Results: In macrophages, GLP-2 blunted the effect of LPS on protein and mRNA expression levels of iNOS, COX-2, TNF- $\alpha$, IL-1 $\beta$ and IL-6. Pre-incubation of macrophages with GLP-2 also blunted LPS-induced IKB- $\alpha$ degradation, IKB- $\alpha$ phosphorylation and NF-KB translocation. In the presence of GLP-2, the effect of LPS treatment on ERK phosphorylation was also profoundly blunted. GLP-2 did, however, not significantly modify the effects of LPS on p38 and JNK activities. Conclusions: These findings demonstrate that in LPS primed macrophages, GLP-2 reduced pro-inflammatory enzymes and cytokine production via mechanisms involving the suppression of NF-KB activity and ERK phosphorylation.
\end{abstract}

S. Xie, B. Liu, S. Fu, W. Wang and Y. Yin contributed equally. 


\section{Introduction}

Macrophages are highly heterogeneous hematopoietic cells found in nearly every tissue in the body [1]. Canonically, these cells have been defined as the sentinels of the innate immune system, monitoring the varied tissue milieu for early signs of infection or tissue damage. Despite the daunting array of inputs, macrophage responses are coordinated through two distinct and mutually exclusive activation programs, termed classical (or M1) and alternative (or M2) $[2,3]$. These activation programs were initially defined by their antimicrobial activities. Classical activation occurs in response to products derived from or associated with bacterial infections, such as lipopolysaccharide (LPS) and interferon $\gamma$ (IFN- $\gamma$ ), and results in highly inflammatory macrophages with high phagocytic and bactericidal potential $[2,4]$. In contrast, alternative activation occurs in response to products derived from or associated with parasitic infections, such as Schistosoma egg antigen, interleukin-4 (IL-4) and interleukin-13 (IL-13), and promotes anti-parasitic functionalities tissue repair and remodeling [5]. Microbial antigens lead to the classical activated macrophages (M1) and the consequent release of pro-inflammatory and/or cytotoxic factors such as tumor necrosis factor $\alpha$ (TNF- $\alpha$ ), interleukin-1 $\beta$ (IL-1 $\beta$ ), interleukin-6 (IL-6), inducible nitric oxide synthase (iNOS) and cyclooxygenase-2 (COX-2), in tissues. These pro-inflammatory cytokines and mediators released from macrophages are vital to the regulation of the immune response, but the dysregulation of their production can lead to pathological conditions, such as septic shock, rheumatoid arthritis and other chronic inflammatory diseases [6].

LPS is a bacterial endotoxin used to study experimentally induced inflammation. Mechanistically, LPS stimulates toll-like receptor 4 (TLR4) in various cells, including macrophages, to activate nuclear factor- $\kappa \mathrm{B}(\mathrm{NF}-\kappa \mathrm{B})$ and mitogen-activated protein kinases (MAPKs), which are classified into at least three components: extracellular signal-regulated kinases (ERKs), c-Jun N-terminal kinase (JNK) and p38 MAPK [7]. MAPKs have been implicated in the release of immune-related cytotoxic factors, such as iNOS, COX-2 and proinflammatory cytokines (TNF- $\alpha$, IL-1 $\beta$, IL-6) $[8,9]$.

Glucagon-like peptide 2 (GLP-2), a 33-amino acid peptide (GLP-2 (1-33)), belongs to the so-called proglucagon-derived peptides (PGDPs), which originate from tissue-specific post-translational processing by convertases of proglucagon. GLP-2 (1-33) is synthesized in the gastrointestinal tract in the L-cells of the small intestine and colon $[10,11]$. Studies in rodents treated with GLP-2 (1-33) or synthetic analogs of the peptide demonstrate that GLP2 promotes the growth of the small intestine [12-14], improves intestinal wound healing through in a transforming growth factor $\beta$ (TGF- $\beta$ )-mediated process [15], decreases mortality in indomethacin-induced murine enteritis and enhances enteric adaptation in rodent shortbowel models [16-19]. In addition to these intestinal trophic effects, other studies have demonstrated that GLP-2 attenuates inflammation [20]. However, the underlying molecular mechanisms have not been resolved.

The present study attempted to elucidate the anti-inflammatory potential of GLP2 on the inflammatory response induced by LPS in murine peritoneal macrophages. The involvement of I $\mathrm{B}-\alpha, \mathrm{NF}-\kappa \mathrm{B}$ and MAPKs was also examined to further investigate the underlying mechanisms. We showed that LPS-induced pro-inflammatory enzymes and proinflammatory cytokines in peritoneal macrophages were significantly reduced by treatment with GLP-2 and the inhibitory effect of GLP-2 on pro-inflammatory enzymes and proinflammatory cytokines was mediated by ERK phosphorylation and NF- $\kappa$ B signaling.

\section{Materials and Methods}

\section{Animals}

Balb/c female mice (6-8 weeks old, 17-21 g) were obtained from the Center of Experimental Animal of Baiqiuen Medical College of Jilin University (Jilin, China) and maintained in plastic cages under conventional conditions. Water and pellet diets were supplied ad libitum. Studies were performed in accordance with the guidelines established by the Jilin University Institutional Animal Care and Use Committee. 
Table 1. The primer sequences of $\beta$-actin, GLP-2R, iNOS, COX-2, TNF- $\alpha$, IL-1 $\beta$ and IL- 6

\begin{tabular}{|c|c|c|}
\hline Gene & Sequences & Length (bp) \\
\hline$\beta$-actin & $\begin{array}{l}\text { (F)5'- GTCAGGTCATCACTATCGGCAAT -3' } \\
\text { (R)5'- AGAGGTCTTTACGGATGTCAACGT -3' }\end{array}$ & 147 \\
\hline GLP-2R & $\begin{array}{l}\text { (F)5'- GGTCCTCCTGCACTACTTT -3' } \\
\text { (R)5'- CCAGGGAATAACAAACAGC -3' }\end{array}$ & 163 \\
\hline iNOS & $\begin{array}{l}\text { (F)5'- GAACTGTAGCACAGCACAGGAAAT -3' } \\
\text { (R)5'- CGTACCGGATGAGCTGTGAAT -3' }\end{array}$ & 158 \\
\hline $\operatorname{coX}-2$ & $\begin{array}{l}\text { (F) 5'- CAGTTTATGTTGTCTGTCCAGAGTTTC -3' } \\
\text { (R)5'- CCAGCACTTCACCCATCAGTT -3' }\end{array}$ & 127 \\
\hline TNF- $\alpha$ & $\begin{array}{l}\text { (F) 5'- GCAACTGCTGCACGAAATC -3' } \\
\text { (R) 5'- CTGCTTGTCCTCTGCCCAC - -3' }\end{array}$ & 136 \\
\hline IL- $1 \beta$ & $\begin{array}{l}\text { (F) 5'- GTTCCCATTAGACAACTGCACTACAG -3' } \\
\text { (R)5'- GTCGTTGCTTGGTTCTCCTTGTA -3' }\end{array}$ & 139 \\
\hline IL-6 & $\begin{array}{l}\text { (F) 5'-CCAGAAACCGCTATGAAGTTCC - -3' } \\
\text { (R)5'- GTTGGGAGTGGTATCCTCTGTGA - -3' }\end{array}$ & 138 \\
\hline
\end{tabular}

Peritoneal macrophages cultures and treatments

Peritoneal exudates were obtained from Balb/c female mice by lavage 4 days after an intraperitoneal injection of $4 \mathrm{ml}$ sterile $4 \%$ thioglycollate broth. After washing with RPMI 1640 medium, the cell suspensions were centrifuged at $800 \mathrm{~g}$ at $4{ }^{\circ} \mathrm{C}$ for $5 \mathrm{~min}$. The red blood cells were eliminated by ACK buffer and the cells were washed and resuspended in RPMI 1640 supplemented with 10\% inactivated FBS, 10 mM HEPES, 2 $\mathrm{mM}$ glutamine, and $100 \mathrm{U} / \mathrm{ml}$ penicillin $-100 \mathrm{mg} / \mathrm{ml}$ streptomycin. Peritoneal macrophages were plated in 6-cm tissue culture dishes at $37{ }^{\circ} \mathrm{C}$ in a $5 \% \mathrm{CO}_{2}$ humidified atmosphere. Changes in cell morphology and growth conditions were carefully monitored using an inverted microscope. Macrophages were precultured in serum-free RPMI 1640 medium for $24 \mathrm{~h}$ to reduce mitogenic effects. Macrophages were pretreated with various concentrations of GLP-2 for $1 \mathrm{~h}$ and stimulated with LPS.

\section{Cell viability assay}

Cell viability was determined by MTT assay. Briefly, macrophages were seeded into 96-well plates at a density of $2 \times 10^{4}$ cells per well $24 \mathrm{~h}$ before treatment. Cells were treated with various concentrations of GLP-2 for the indicated time periods followed by incubating with $5 \mathrm{mg} / \mathrm{ml}$ of MTT working solution for 4 $\mathrm{h}$ at $37^{\circ} \mathrm{C}$. After added $100 \mu \mathrm{l}$ of DMSO to dissolve the crystals, the absorbance of each well at $570 \mathrm{~nm}$ was measured using a Synergy 2 Multi-Mode Microplate Reader (BIO-TEK, INC). Three replicates were carried out for each of the different treatments.

\section{RNA extraction, reverse transcriptase PCR and quantitative real-time PCR analysis}

Total RNA was extracted from peritoneal macrophages using TRIzol (Invitrogen, Carlsbad, CA, USA) according to the supplier's protocol. Complementary DNA (cDNA) was generated from $5 \mu \mathrm{g}$ of total RNA using PrimeScript RT reagent Kit with gDNA Eraser (Takara Shuzo Co, Ltd, Kyoto, Japan). The mRNA levels of various genes were evaluated by quantitative polymerase chain reaction (qRT-PCR) analysis and the SYBR Green QuantiTect RT-PCR Kit (Roche, South San Francisco, CA, USA), performed in triplicate for each sample. The relative expression levels of iNOS, COX-2, TNF- $\alpha$, IL-1 $1 \beta$ and IL- 6 were calculated relative to $\beta$-actin using the comparative cycle threshold method. The primer sequences for the tested genes are shown in Table 1.

\section{ELISA}

Macrophages seeded in 24-well plates were pretreated with various concentrations of GLP-2 for $1 \mathrm{~h}$ followed by stimulation with LPS $(100 \mathrm{ng} / \mathrm{ml})$ for another $12 \mathrm{~h}$. After stimulation, the culture media were collected and centrifuged at $13,000 \mathrm{~g}$ for $3 \mathrm{~min}$. The levels of cytokines in the supernatants for TNF- $\alpha$, IL$1 \beta$ and IL- 6 were determined by ELISA (BioLegend, San Diego, CA, USA) according to the manufacturer's instructions. Three replicates were performed for each of the different treatments.

Western blot analysis

Cells were harvested with ice-cold PBS and centrifuged at 13,000×g for 3 min at $4{ }^{\circ} \mathrm{C}$. Nuclear and cytosolic extracts were prepared using a Nuclear and Cytoplasmic Protein Extraction Kit (Beyotime Institute 
of Biotechnology, Jiangsu, China) according to the manufacturer's instructions. Protein concentrations were measured using a bicinchoninic acid protein assay kit (Beyotime Co, China). Equal amounts of lysates $(50 \mu \mathrm{g})$ were separated on $10 \%$ SDS-PAGE. Proteins were transferred onto immunoblot polyvinylidene difluoride membranes (Chemicon International, Millipore, Billerica, MA), and the membranes were blocked with 5\% BSA in Tris-buffered saline with $0.1 \%$ Tween (TBS-T) for $2 \mathrm{~h}$ and incubated overnight at $4{ }^{\circ} \mathrm{C}$ with the following primary antibodies: iNOS (1:2000), COX-2 (1:1000) (Abcam, Cambridge, CA, USA), phosphoERK1/2 (1:1000), ERK1/2 (1:1000), phospho-p38 (1:1000), p38 (1:1000), phospho-JNK (1:1000), JNK (1:1000), IкB- $\alpha$ (1:1000), phospho-IкB- $\alpha$ (1:1000) (Cell Signaling Technology, Danvers, MA, USA), rabbit anti-mouse NF-кB/RelA (1:1000; Santa Cruz Biotechnology), PCNA (1:1000; Santa Cruz Biotechnology), or $\beta$-actin (1:2000; Santa Cruz Biotechnology). Blots were washed four times for 15 min each in TBS-T and incubated with horseradish peroxidase-labeled secondary goat anti-rabbit (1:2000; Santa Cruz Biotechnology) or rabbit anti-goat (1:2000; Santa Cruz Biotechnology) for $1 \mathrm{~h}$. Blots were again washed four times for 15 min each in TBS-T. Finally, blots were developed using the enhanced chemiluminescence (Pplygen Co, China) method.

\section{Statistical analyses}

The results are expressed as the means \pm SD. Data were analyzed using the statistical software package SPSS 12.0(SPSS Inc, Chicago, IL, USA). Groups were compared by one-way analysis of variance (ANOVA) followed by the least significant difference test. A P value of less than 0.05 was considered statistically significant, and values less than 0.01 were considered markedly significant.

\section{Results}

GLP-2 inhibits LPS-stimulated expression of iNOS and COX-2 proteins and mRNA in macrophages

iNOS and COX-2 are two important pro-inflammatory proteins correlated with LPS stimulation in macrophages. Macrophages were pretreated with $\operatorname{GLP}-2\left(10^{-9}, 10^{-8}, 10^{-7}\right.$ and $\left.10^{-6} \mathrm{M}\right)$ for $1 \mathrm{~h}$ and stimulated with LPS $(100 \mathrm{ng} / \mathrm{ml})$ for $4 \mathrm{~h}$ to investigate the effect of GLP-2 on the activation of LPS-stimulated macrophages. iNOS and COX-2 were examined by Western blotting and qRT-PCR. GLP-2 notably dose-dependently inhibited the increased expression of iNOS and COX-2 proteins and mRNA stimulated by LPS (Fig. 1).

GLP-2 attenuates LPS-stimulated the production of the pro-inflammatory cytokines TNF- $\alpha, I L-1 \beta$ and $I L-6$ at the transcriptional and translational levels in macrophages

Pro-inflammatory cytokines (including TNF- $\alpha$, IL-1 $\beta$ and IL-6) play important roles in the inflammatory process. Macrophages were stimulated with LPS $(100 \mathrm{ng} / \mathrm{ml})$ in the presence or absence of GLP-2 $\left(10^{-9}, 10^{-8}, 10^{-7}\right.$ and $\left.10^{-6} \mathrm{M}\right)$ to investigate whether GLP-2 represses the production of these pro-inflammatory cytokines. Fig. 2 shows that the significant increases in the proteins and mRNA levels of TNF- $\alpha$ (Figs. 2A, 2B), IL-1 $\beta$ (Fig. 2E) and IL-6 (Figs. 2C, $2 D)$ resulting from the LPS stimulation were inhibited by GLP-2 in a dose-dependent manner in macrophages. The secretion of IL-1 $\beta$ was not detected in cell culture supernatants. We investigated the dose effect of GLP-2 on cell viability by the MTT assay to determine the GLP-2 cytotoxicity. Macrophages were incubated with various doses of GLP-2 for $24 \mathrm{~h}$. The MTT assay showed that GLP-2 did not affect cell viability even at a high concentration of $10^{-6} \mathrm{M}$ (Fig. 2F), which demonstrates that GLP-2 at non-cytotoxic levels suppressed LPSinduced inflammatory responses in macrophages via attenuation of iNOS, COX-2 and proinflammatory cytokines expression in our experiments.

\section{Effects of GLP-2 are not mediated by the GLP-2 receptor}

The GLP-2 receptor (GLP-2R) is the functional receptor of GLP-2. We investigated whether GLP-2R mRNA was expressed in macrophages to analyze whether this receptor mediates anti-inflammation of GLP-2. Fig. 3 shows that GLP-2R mRNA was not detected in macrophages. Therefore, GLP-2 can not act on macrophages via the GLP-2 receptor. 


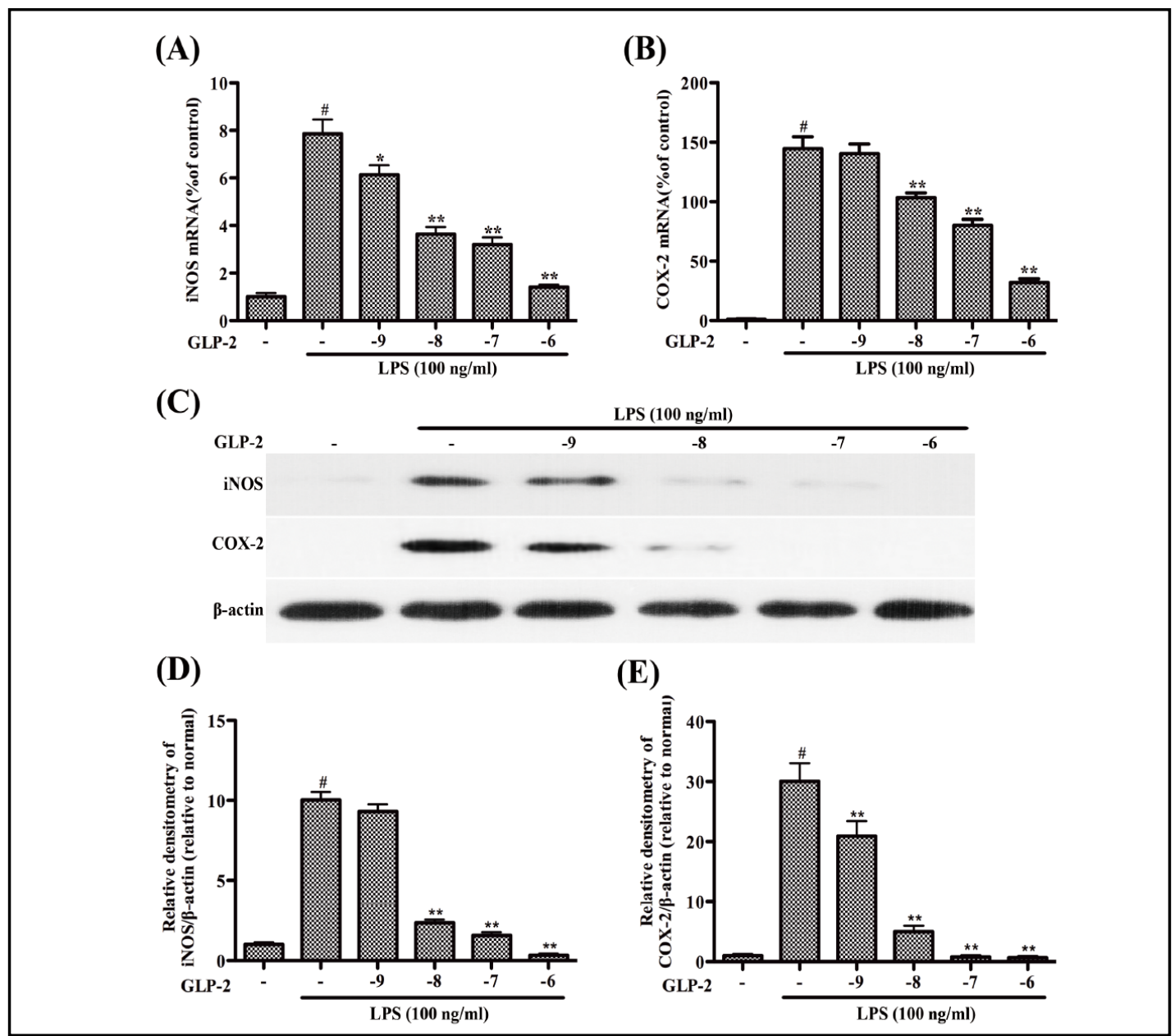

Fig. 1. Effects of GLP-2 on LPS-induced expression of proteins and mRNA of iNOS and COX-2 in macrophages. Macrophages were pretreated with GLP-2 $\left(10^{-9}, 10^{-8}, 10^{-7}\right.$ and $\left.10^{-6} \mathrm{M}\right) 1 \mathrm{~h}$ prior to incubation of LPS $(100$ $\mathrm{ng} / \mathrm{mL}$ ) for $4 \mathrm{~h}$. Proteins and mRNA of iNOS and COX-2 were determined by Western blotting and qRT-PCR. Panels A and B show mRNA of iNOS (A) and COX-2 (B). Panels C, D and E show the protein expression of iNOS $(C, D)$ and COX-2 (C, E), with levels normalized to $\beta$-actin. The results are expressed as the means \pm SD for each group from three independent experiments. "Significant compared to control alone, $\mathrm{p}<0.05$. ${ }^{*} \mathrm{p}<0.05$ and ${ }^{* *} \mathrm{p}<0.01$ versus the GLP-2-untreated LPS-stimulated group.

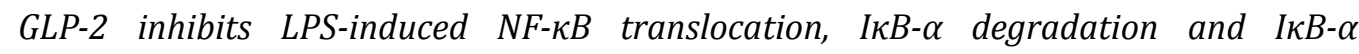
phosphorylation

The NF- $\mathrm{BB}$ pathway is a key mediator of inflammation, and it is activated via toll-like receptors (TLRs) which increase pro-inflammatory enzymes (iNOS and COX-2) and proinflammatory cytokines (TNF- $\alpha$, IL-1 $\beta$ and IL-6). The study examined the effect of GLP-2 on NF- $\kappa B$ to further elucidate the mechanisms of GLP-2 on the inhibition of expression of iNOS, COX-2 and pro-inflammatory cytokines in macrophages. Our previous study of LPS stimulation

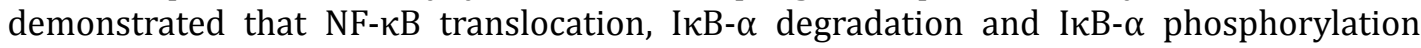
reached a maximum at $30 \mathrm{~min}$ and then decreased gradually in macrophages. Macrophages were pretreated with various doses of GLP-2 $\left(10^{-9}, 10^{-8}, 10^{-7}\right.$ and $\left.10^{-6} \mathrm{M}\right)$ for $1 \mathrm{~h}$ and stimulated with LPS (100 ng/ml) for $30 \mathrm{~min}$. Nuclear and cytosolic extracts were isolated, and NF- $\kappa B$ p65 subunits in the nuclear and cytosolic fractions were quantified by Western blotting. Fig. 4 shows that LPS sharply increased the translocation of NF- $\kappa B$ p65 from the cytosol to the nucleus, and this increase was inhibited dose-dependently by pretreatment with GLP-2. The LPS-mediated translocation of NF- $\mathrm{KB}$ to the nucleus is preceded by the phosphorylation 
Fig. 2. Effects of GLP-2 on LPS - induced expression of proteins and mRNA of TNF- $\alpha, \quad$ IL-1 $\beta$ and IL-6 in macrophages. Macrophages were pretreated with GLP-2 $\left(10^{-9}, 10^{-8}, 10^{-7}\right.$ and $10^{-6} \mathrm{M}$ ) 1 $\mathrm{h}$ prior to incubation of LPS (100 ng/mL) for $4 \mathrm{~h}$ (mRNA) or $12 \mathrm{~h}$ (protein). Proteins and mRNA of TNF- $\alpha$ (A, B), IL-6 (C, D) and IL-1 $\beta$ (E) were determined by ELISA and qRT-PCR. The results are expressed as means \pm SD for each group from three in-

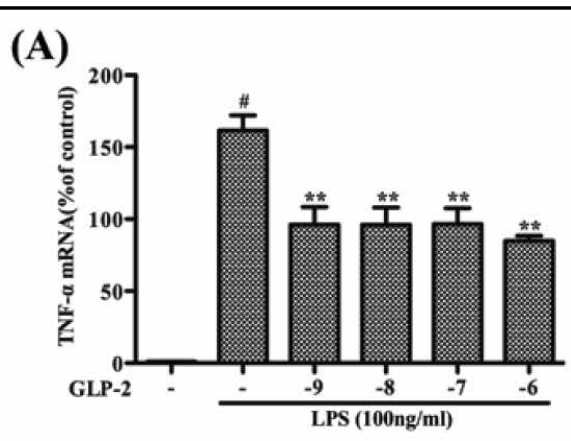

(B)

(C)

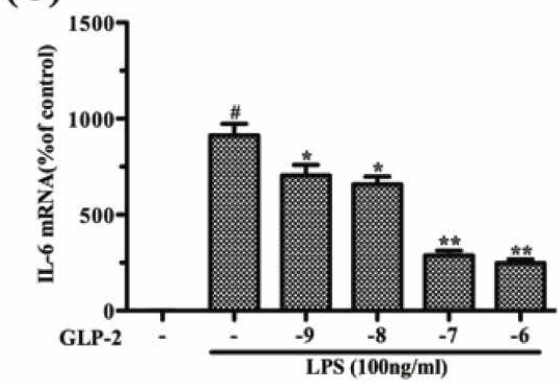

(E)

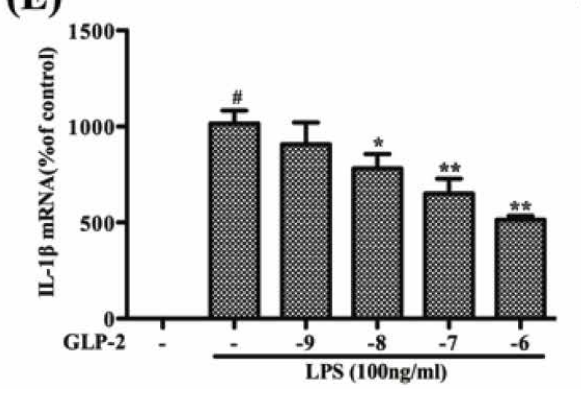

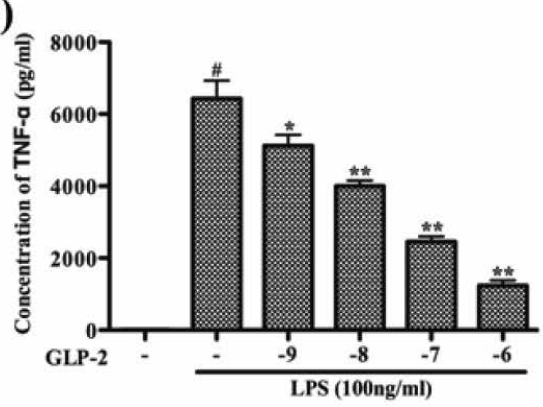

(D)

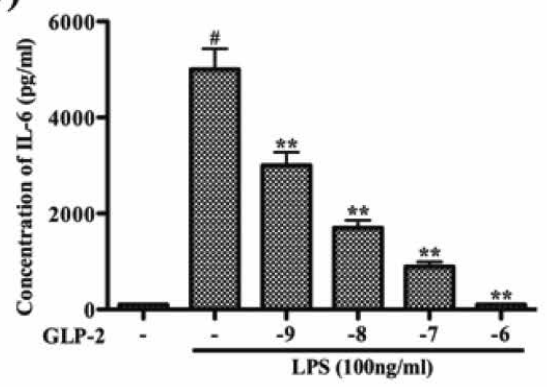

(F)

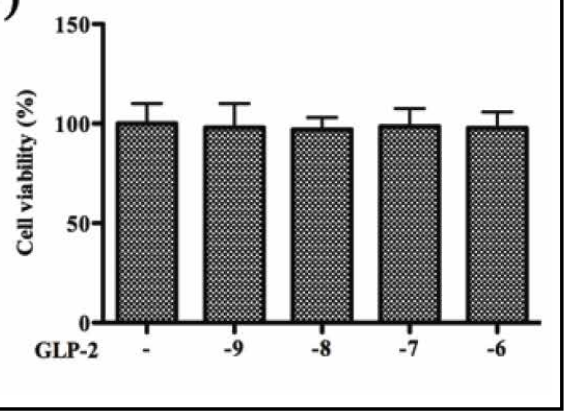
dependent experiments. Macrophages cells were treated with the indicated concentrations of GLP-2 for 24 h. Cell viability was evaluated using the MTT assay, and the results are expressed as the percentage of surviving cells over the control group (F). \# Significant compared to control alone, $\mathrm{p}<0.05$. ${ }^{*} \mathrm{p}<0.05$ and ${ }^{* *} \mathrm{p}<0.01$ versus the GLP-2-untreated LPS-stimulated group.

Fig. 3. Expression of GLP2R mRNA in macrophages. RT mixtures from colon (positive control) and macrophages (M) were performed to detect GLP2R mRNA expression by PCR amplification. PCR products were visualized using $2 \%$ agarose gel electrophoresis, and the expected 163-bp GLP-2R was detected in the colon, but not in macrophages.

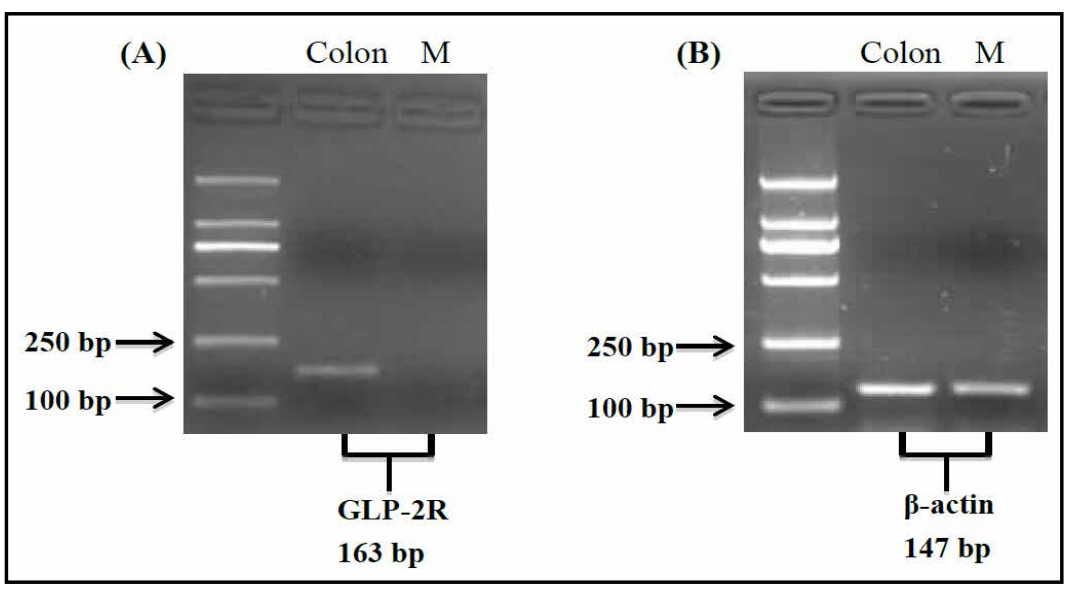

and degradation of IкB- $\alpha$. Therefore, we also examined protein levels of phosphorylation and degradation of IкB- $\alpha$ by Western blotting analysis. GLP-2 dose-dependently inhibited 


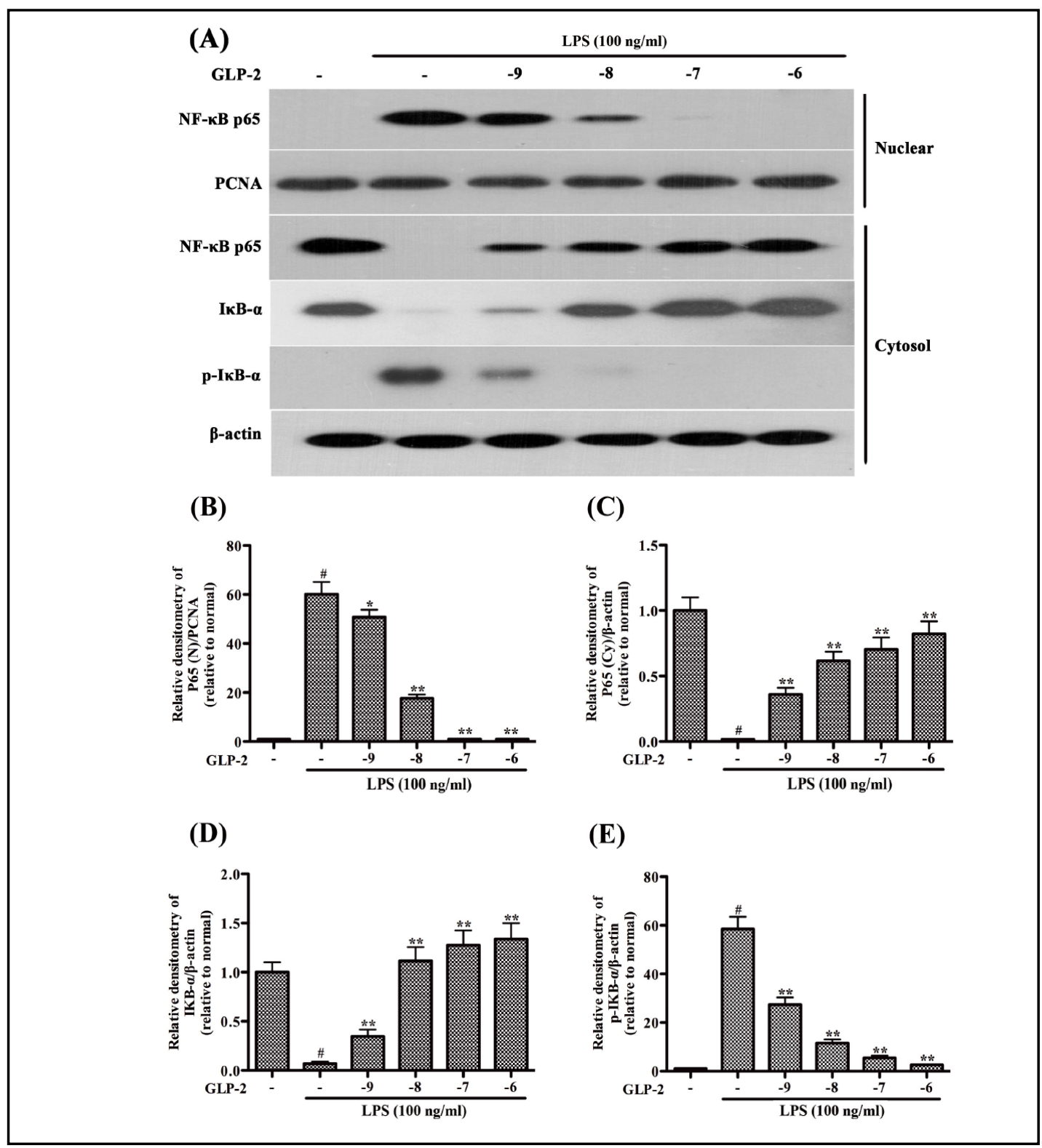

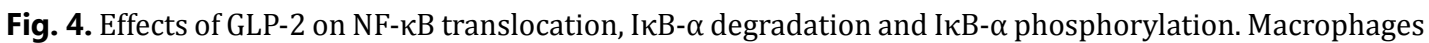
were pretreated with GLP-2 $\left(10^{-9}, 10^{-8}, 10^{-7}\right.$ and $\left.10^{-6} \mathrm{M}\right) 1 \mathrm{~h}$ prior to incubation with LPS $(100 \mathrm{ng} / \mathrm{mL})$ for 30

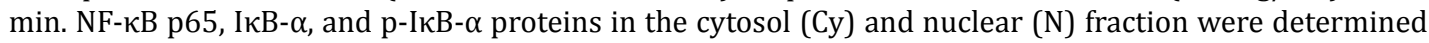
by Western blotting. Each immunoreactive band was digitized, and the results are expressed as a ratio of $\beta$-actin or PCNA levels. The ratio of the normal group band was set to 1.00. Data are expressed as the means \pm SD of three independent experiments. ${ }^{*}$ Significant compared to control alone, $\mathrm{p}<0.05$. ${ }^{* *} \mathrm{P}<0.01,{ }^{*} \mathrm{P}<0.05$, significantly different compared to the GLP-2-untreated LPS-stimulated group.

the LPS-induced phosphorylation and degradation of IкB- $\alpha$ (Fig. 4). These results indicated that GLP-2 suppresses LPS-induced inflammatory responses, at least in part, through the

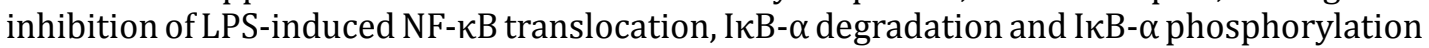
in macrophages.

GLP-2 suppresses LPS-induced ERK phosphorylation in macrophages

MAPK signaling pathways play an important role in the regulation of inflammatory mediator production. Therefore, we investigated the effects of GLP-2 on the activation of 


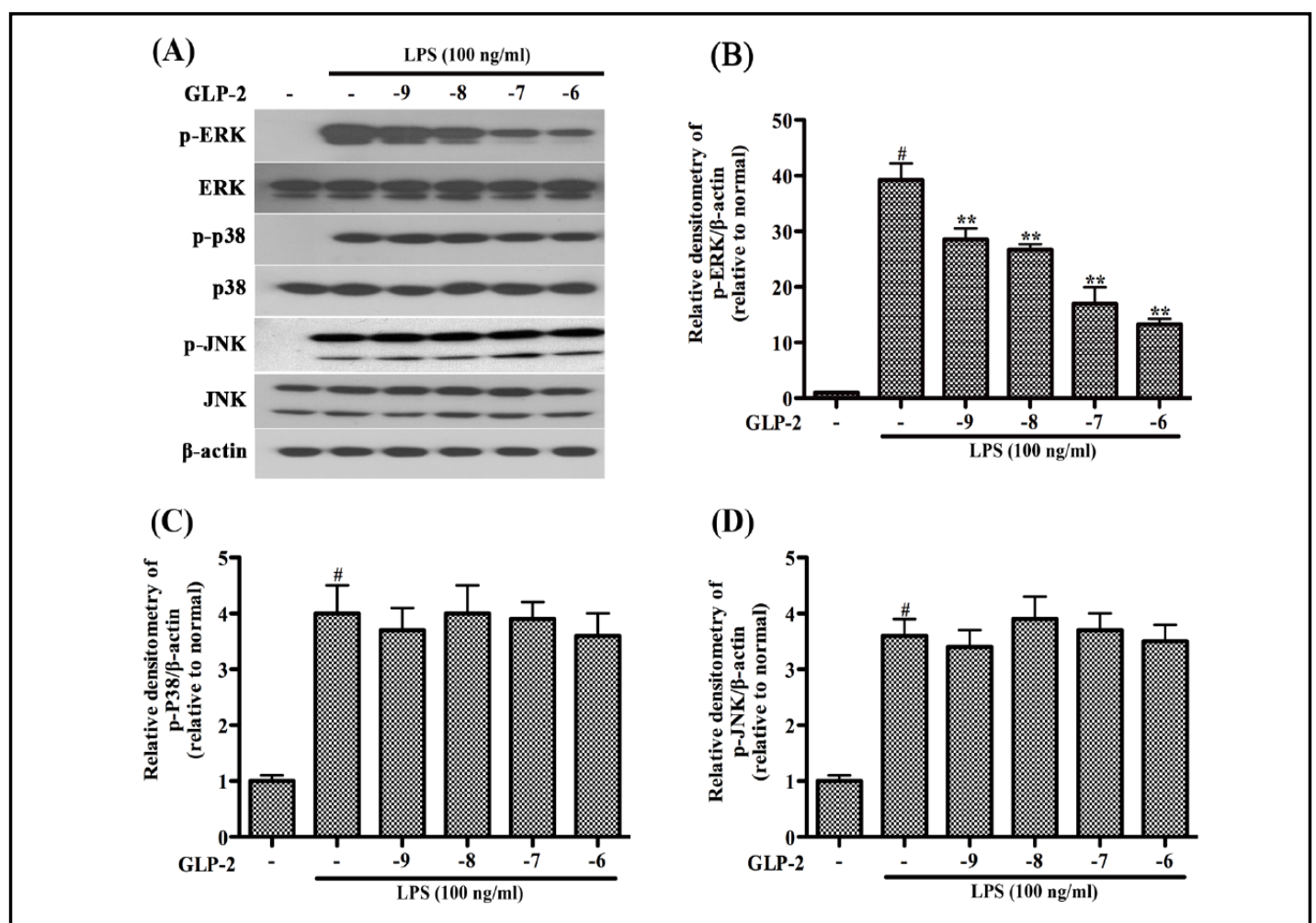

Fig. 5. Effects of GLP-2 on LPS-induced phosphorylation of MAPKs. Macrophages were pretreated with or without GLP-2 $\left(10^{-9}, 10^{-8}, 10^{-7}\right.$ and $\left.10^{-6} \mathrm{M}\right)$ for $1 \mathrm{~h}$ and incubated with LPS $(100 \mathrm{ng} / \mathrm{mL})$ for $30 \mathrm{~min}$. Cell lysates were prepared and subjected to Western blotting using p-JNK54/46, p-p38, or p-ERK1/2 antibodies. Each immunoreactive band was digitized and the results are expressed as a ratio of $\beta$-actin levels. The ratio of the normal group band was set to 1.00. Data are expressed as the means \pm SD of three independent experiments. " Significant compared to control alone, $\mathrm{p}<0.05$. ${ }^{* *} \mathrm{P}<0.01,{ }^{*} \mathrm{P}<0.05$, significantly different compared to the GLP-2-untreated LPS-stimulated group.

phospho-ERK, phospho-JNK and phospho-p38. Our previous study of LPS stimulation demonstrated that the phosphorylation of JNK, ERK and p38-MAPK reached a maximum at $30 \mathrm{~min}$ and then decreased gradually in macrophages. Macrophages were pretreated with various doses of GLP-2 $\left(10^{-9}, 10^{-8}, 10^{-7}\right.$ and $\left.10^{-6} \mathrm{M}\right)$ for $1 \mathrm{~h}$ and stimulated with LPS (100 $\mathrm{ng} / \mathrm{ml}$ ) for $30 \mathrm{~min}$. Cytoplasmic proteins were extracted, and the phosphorylation of $\mathrm{p} 38$, ERK1/2 and JNK was examined by Western blotting. The results showed that LPS sharply increased the phosphorylation of ERK, p38-MAPK and JNK, and ERK phosphorylation was inhibited dose-dependently by pretreatment with GLP-2 (Figs. 5A, 5B). However, the increased phosphorylation of JNK (Figs. 5A, 5D) and p38-MAPK (Figs. 5A, 5C) were not attenuated by LPS stimulation. The levels of non-phosphorylated MAPK isoforms did not vary remarkably between groups.

\section{Discussion}

GLP-2 is an intestinotrophic peptide that is secreted by enteroendocrine L-cells in response to nutrient ingestion [21]. GLP-2 has several beneficial actions in the gut, including increased mucosal growth, blood flow and digestive and absorptive function $[12,13,22$, 23]. Although recent reports have shown that GLP-2 exerts an anti-inflammatory action [14, 
$20,24,25]$, the underlying molecular mechanisms have not been resolved. Therefore, more detailed mechanisms must be elucidated. This study analyzed the molecular mechanism by which GLP-2 suppresses inflammation following LPS stimulation in macrophages, and we found that GLP-2 significantly inhibited LPS-induced enhancement of pro-inflammatory enzymes (iNOS and COX-2) and pro-inflammatory cytokines (TNF- $\alpha$, IL-1 $\beta$ and IL-6) expression in macrophages at the mRNA and protein levels, which provides an underlying mechanism for the anti-inflammatory effects of GLP-2 in vitro.

First, we examined the effect of GLP-2 on iNOS and COX-2 expression, which are two important inflammatory factors [9]. GLP-2 $\left(10^{-9}, 10^{-8}, 10^{-7}\right.$ and $\left.10^{-6} \mathrm{M}\right)$ significantly inhibited the protein and mRNA expression of iNOS and COX-2 in a dose-dependent manner in LPS-stimulated macrophages, which suggests a possible beneficial effect of GLP-2 via the attenuation of macrophages activation and the subsequent production of inflammatory mediators. Therefore, GLP-2 would be beneficial for delaying the progression of inflammatory diseases.

Macrophages activation cause the release of pro-inflammatory cytokines, including TNF- $\alpha$, IL-1 $\beta$ and IL-6 [26]. This pro-inflammatory response by macrophages is protective in fighting off pathogens such as bacteria, in normal circumstances. In contrast, under pathological conditions induced by certain insults, including oxidative stressand excitotoxicity, macrophages can be over-stimulated and produce an excess of pro-inflammatory cytokines, which can lead to pathological conditions, such as septic shock, rheumatoid arthritis, and other chronic inflammatory diseases [27]. This study investigated whether GLP-2 inhibits the LPS-induced production of pro-inflammatory cytokines in macrophages. Our data suggest that GLP-2 significantly reduced LPS-induced protein and mRNA expression levels of TNF- $\alpha$, IL-1 $\beta$ and IL- 6 . We detected the mRNA expression of IL-1 $\beta$, but not protein secretion, which may be relevant to the maturation of IL-1 $\beta$. In mammals, inflammasomes are composed of sensory NLRs, an adaptor protein called ASC, and the caspase- 1 protease, and their activation results in the processing of pro-caspase 1 into activated caspase 1 , which cleaves pro-IL-1 $\beta$ into the secreted IL-1 $\beta$ cytokine $[28,29]$. The concentration of LPS used in this paper may have been too low to initiate inflammasome assembly, which is essential for the maturation of IL-1 $\beta$. These results suggest that GLP-2 has the potential to act directly on macrophages to inhibit pro-inflammatory cytokines production.

The GLP-2R is a 7-transmembrane domain GPCR belonging to the glucagons-secretin receptor superfamily that shares sequence homology with glucagon and GLP-1 receptors [30]. GLP-2 has been identified as an endogenous ligand of the receptor [31]. Yusta B et al. failed to detect GLP-2R mRNA transcripts in a variety of intestinal epithelial cell lines, including Caco-2 and T84 cells using RT-PCR analysis [32]. GLP-2 produced a dose-dependent $(10 \mathrm{nM}$ to $10 \mu \mathrm{M})$ increase in $\left[{ }^{3} \mathrm{H}\right]$ thymidine incorporation in both of these cell lines [3335]. In addition, pertussis toxin inhibits GLP-2-induced proliferation in Caco-2 cells [36], which suggests the possible existence of an as yet unidentified second GLP-2R for GLP-2 to couple to different G-protein subunits and activate multiple signaling pathways, and this type of non-classical signaling has not been observed with other PGDP peptides[37]. We investigated GLP-2R mRNA expression in macrophages to analyze whether this receptor mediated the anti-inflammation effects of GLP-2. Unexpectedly, GLP-2R mRNA was not detected in macrophages, which suggests that another receptor mediates inhibition of proinflammatory mediators of GLP-2.

$\mathrm{NF}-\kappa \mathrm{B}$ is clearly one of the most important regulators of pro-inflammatory gene expression. The synthesis of cytokines, such as TNF- $\alpha$, IL-1 $\beta$ and IL-6, is mediated by NF- $\kappa$ B, as is the expression of COX-2 and iNOS [9]. In resting cells, NF- $\kappa B$ dimers are sequestered in the cytosol by inhibitory proteins of the IкB family [38]. The crucial step in NF- $\kappa \mathrm{B}$ activation is the phosphorylation of I $\mathrm{KB}$ proteins by the activating I $\kappa \mathrm{B}$ kinase complex. Inhibitor of nuclear factor kappa-B kinase 2 (IKK2) is the critical kinase subunit inducing the canonical signaling pathway, which is essentially involved in the regulation of inflammation. The phosphorylation of inhibitory I $\mathrm{\kappa} B$ proteins initiates their ubiquitination and subsequent proteasomal degradation, followed by the release and nuclear translocation of active NF- $\kappa \mathrm{B}$ 
dimers, which induces the expression of NF-кB target genes [39-41]. We examined whether GLP-2-mediated signaling pathways modulate NF- $\kappa B$ signaling to study the molecular mechanisms underlying the anti-inflammatory effect of GLP-2. Incubation of macrophages

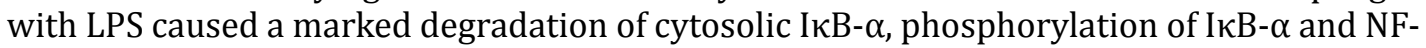
$\kappa B$ p65 translocation into the nucleus, but pretreatment with GLP-2 significantly inhibited I $\kappa \mathrm{B}-\alpha$ degradation, I $\mathrm{\kappa} \mathrm{B}-\alpha$ phosphorylation and NF- $\kappa \mathrm{B}$ p65 nuclear translocation. These results indicated that GLP-2 suppresses LPS-induced inflammatory responses, at least in part, through the inhibition of LPS-induced IкB- $\alpha$ degradation, IкB- $\alpha$ phosphorylation and $\mathrm{NF}-\kappa \mathrm{B}$ p65 nuclear translocation in macrophages.

MAPKs are a family of serine/threonine protein kinases responsible for most cellular responses to cytokines and external stress signals, and these kinases are crucial for the regulation of the production of inflammation mediators [42]. We investigated the effect of GLP-2 on the activation (phosphorylation) of three MAPKs induced by LPS in macrophages to further elucidate the mechanisms of GLP-2 on the inhibition of expression of iNOS, COX-2 and pro-inflammatory cytokines in macrophages. The results showed LPS sharply increased the phosphorylation of ERK, p38-MAPK and JNK, and ERK phosphorylation was inhibited dose-dependently by pretreatment with GLP-2. However, the increased phosphorylation of JNK and p38-MAPK after LPS stimulation was not attenuated. Elaine de Heuval et al. have demonstrated that GLP-2 regulated VIP expression via increasing the phosphorylation of ERK1/2 in enteric neurons that naturally express the GLP-2R [43]. T. Angelone proved that GLP-2 increase phosphorylation of ERK1/2 in the rat heart that naturally expresses the GLP-2R [44]. GLP-2 induces proliferation of Caco2 cells that did not express the GLP$2 \mathrm{R}$ by increasing phosphorylation of ERK1/2 [45]. However, Yustaet al. showed that GLP-2 inhibited ERK1/2 activity in BHK fibroblasts transfected with the rat GLP-2 receptor [46]. So, the effect of GLP-2 on phosphorylation of ERK1/2 is controversial now. In our study, only treatment with GLP-2 did not affect phosphorylation of ERK1/2. However, GLP-2 can inhibit LPS induced phosphorylation of ERK1/2. The apparent divergence of the actions of the effects of GLP-2 depending on acting through the native receptor or the putative novel signaling pathway. Additional studies will be required to elucidate the intracellular pathways involved in the GLP-2 effects on phosphorylation of ERK1/2. Our results suggested that the GLP-2-mediated attenuation of pro-inflammatory mediators was associated with the downregulation of ERK phosphorylation.

Macrophage polarization is driven by cues in the tissue microenvironment, which can include cytokines, growth factors, and microorganism-associated molecular patterns. At least in vitro, LPS-activated macrophages after a few hours become unable to reactivate a large fraction of pro-inflammatory genes following restimulation [47]. However, they retain the ability to induce the expression of many other genes, including IL-10 [48], for example. This altered state of responsiveness to secondary stimulation is commonly referred to as endotoxin tolerance and results in a global and sustained switch of the gene expression program from a pro-inflammatory M1 signature to an M2-like anti-inflammatory phenotype [49]. Thus, we evaluated the phenotype transition from M1 to M2 to confirm whether it is related to the decreased production of IL- $1 \beta$, IL- 6 and TNF- $\alpha$. In addition, iNOS is important surface markers of M1 macrophages [50]. As shown in Figure 1, GLP-2 inhibited the gene and protein expression of iNOS in LPS-stimulated macrophages. Our result indicated that GLP-2 might promote a shift from the M1 to M2 macrophage phenotype by decreasing the expression of iNOS in LPS stimulated cells.

In summary, the results of this study provide evidence that GLP-2 might exhibits its anti-inflammatory effects via promoting a shift from the M1 to M2 macrophage phenotype and the suppression of NF- $\kappa \mathrm{B}$ activity and ERK phosphorylation. These findings provide a new molecular insight into the mechanism by which GLP-2 exerts its anti-inflammatory function. Our results suggest that GLP-2 may be an attractive candidate as a therapeutically important anti-inflammatory agent. 


\section{Acknowledgments}

This work was founded by the National Natural Science Foundation of China (Project No. 31272390, 31072100, 31372396), National Key Basic Research Program of China (Project No. 2011CB100805), Jilin Scientific and Technological Development Program (Project No. 201215036, 20130206036NY), and Graduate Innovation Fund of Jilin University (Project No. 2013A81274, 2013A85293).

\section{Disclosure Statement}

The authors declare no conflict of interest.

\section{References}

Gordon S, Taylor PR: Monocyte and macrophage heterogeneity. Nat Rev Immunol 2005;5:953-964. Gordon S: Alternative activation of macrophages. Nat Rev Immunol 2003;3:23-35.

3 Martinez FO, Sica A, Mantovani A, Locati M: Macrophage activation and polarization. Front Biosci 2007;13:453-461.

4 Goerdt S, Politz O, Schledzewski K, Birk R, Gratchev A, Guillot P, Hakiy N, Klemke C-D, Dippel E, Kodelja V: Alternative versus classical activation of macrophages. Pathobiology 2000;67:222-226.

5 Martinez FO, Helming L, Gordon S: Alternative activation of macrophages: An immunologic functional perspective. Annu Rev Immunol 2009;27:451-483.

$>6$ Guha M, Mackman N: Lps induction of gene expression in human monocytes. Cell Signal 2001;13:85-94.

7 Martindale JL, Holbrook NJ: Cellular response to oxidative stress: Signaling for suicide and survival*. J Cell Physiol 2002;192:1-15.

8 Ajmone-Cat M, De Simone R, Nicolini A, Minghetti L: Effects of phosphatidylserine on p38 mitogen activated protein kinase, cyclic amp responding element binding protein and nuclear factor- $\mathrm{kb}$ activation in resting and activated microglial cells. J Neurochem 2003;84:413-416.

-9 Dai J-N, Zong Y, Zhong L-M, Li Y-M, Zhang W, Bian L-G, Ai Q-L, Liu Y-D, Sun J, Lu D: Gastrodin inhibits expression of inducible no synthase, cyclooxygenase-2 and proinflammatory cytokines in cultured lpsstimulated microglia via mapk pathways. PloS one 2011;6:e21891.

10 Buhl T, Thim L, Kofod H, Orskov C, Harling H, Holst JJ: Naturally occurring products of proglucagon 111-160 in the porcine and human small intestine. J Biol Chem 1988;263:8621-8624.

11 Kato Y, Yu D, Schwartz MZ: Glucagonlike peptide-2 enhances small intestinal absorptive function and mucosal mass in vivo. J Pediatr Surg 1999;34:18-21.

12 Brubaker PL, Izzo A, Hill M, Drucker DJ: Intestinal function in mice with small bowel growth induced by glucagon-like peptide-2. Am J Physiol1997;272:E1050-E1058.

13 Drucker DJ, Erlich P, Asa SL, Brubaker PL: Induction of intestinal epithelial proliferation by glucagon-like peptide 2. Proc Natl Acad Sci U S A 1996;93:7911-7916.

14 Drucker DJ, Yusta B, Boushey RP, DeForest L, Brubaker PL: Human [gly2] glp-2 reduces the severity of colonic injury in a murine model of experimental colitis. Am J Physiol 1999;276:G79-G91.

15 Bulut K, Meier J, Ansorge N, Felderbauer P, Schmitz F, Hoffmann P, Schmidt W, Gallwitz B: Glucagon-like peptide 2 improves intestinal wound healing through induction of epithelial cell migration in vitroevidence for a tgf- $\beta$-mediated effect. Regul Pept 2004;121:137-143.

16 Boushey RP, Yusta B, Drucker DJ: Glucagon-like peptide 2 decreases mortality and reduces the severity of indomethacin-induced murine enteritis. Am J Physiol 1999;277:E937-E947.

17 Liu X, Nelson DW, Holst JJ, Ney DM: Synergistic effect of supplemental enteral nutrients and exogenous glucagon-like peptide 2 on intestinal adaptation in a rat model of short bowel syndrome. Am J Clin Nutr 2006;84:1142-1150.

18 Lovshin J, Drucker DJ: New frontiers in the biology of glp-2. Regul Pept2000;90:27-32.

19 Martin G, Beck P, Sigalet D: Gut hormones, and short bowel syndrome: The enigmatic role of glucagon-like peptide-2 in the regulation of intestinal adaptation. World J Gastroenterol 2006;12:4117. 


\section{Cellular Physiology Cell Physiol Biochem 2014;34:590-602 \begin{tabular}{l|l|l} 
DOI: 10.1159/000363025 2014 & \\
and Biochemistry & 2014 S. Karger AG, Basel
\end{tabular}

-20 Ivory CP, Wallace LE, McCafferty D-M, Sigalet DL: Interleukin-10-independent anti-inflammatory actions of glucagon-like peptide 2. Am J Physiol Gastrointest Liver Physiol2008;295:G1202-G1210.

-21 Dubé PE, Brubaker PL: Frontiers in glucagon-like peptide-2: Multiple actions, multiple mediators. Am J Physiol Endocrinol Metab 2007;293:E460-E465.

-22 Bremholm L, Hornum M, Andersen UB, Hartmann B, Holst JJ, Jeppesen PB: The effect of glucagon-like peptide-2 on mesenteric blood flow and cardiac parameters in end-jejunostomy short bowel patients. Regul Pept 2011;168:32-38.

-23 Cheeseman C: Upregulation of sglt-1 transport activity in rat jejunum induced by glp-2 infusion in vivo. Am J Physiol 1997;273:R1965-R1971.

-24 L'Heureux M-C, Brubaker PL: Glucagon-like peptide-2 and common therapeutics in a murine model of ulcerative colitis. J Pharmacol Exp Ther 2003;306:347-354.

25 Sigalet DL, Wallace LE, Holst JJ, Martin GR, Kaji T, Tanaka H, Sharkey KA: Enteric neural pathways mediate the anti-inflammatory actions of glucagon-like peptide 2. Am J Physiol Gastrointest Liver Physiol 2007;293:G211-G221.

26 Liu B, Hong J-S: Role of microglia in inflammation-mediated neurodegenerative diseases: Mechanisms and strategies for therapeutic intervention. J Pharmacol Exp Ther 2003;304:1-7.

27 Nam KN, Park Y-M, Jung H-J, Lee JY, Min BD, Park S-U, Jung W-S, Cho K-H, Park J-H, Kang I: Antiinflammatory effects of crocin and crocetin in rat brain microglial cells. Eur J Pharmacol 2010;648:110116. Drenth JP, van der Meer JW: The inflammasome-a linebacker of innate defense. N Engl J Med 2006;355:730.

29 Martinon F, Pétrilli V, Mayor A, Tardivel A, Tschopp J: Gout-associated uric acid crystals activate the nalp3 inflammasome. Nature 2006;440:237-241.

-30 Munroe DG, Gupta AK, Kooshesh F, Vyas TB, Rizkalla G, Wang H, Demchyshyn L, Yang Z-J, Kamboj RK, Chen $\mathrm{H}$ : Prototypic g protein-coupled receptor for the intestinotrophic factor glucagon-like peptide 2. Proc Natl Acad Sci U S A 1999;96:1569-1573.

-31 Bhatnagar P, Purvis S, Barron-Casella E, DeBaun MR, Casella JF, Arking DE, Keefer JR: Genome-wide association study identifies genetic variants influencing f-cell levels in sickle-cell patients. J Hum Genet 2011;56:316-323.

-32 Yusta* B, Huang* L, Munroe† D, Wolff § G, Fantaske† R, Sharma† S, Demchyshyn† L, Asa § SL, Drucker* DJ: Enteroendocrine localization of glp-2 receptor expression in humans and rodents. Gastroenterology 2000;119:744-755.

33 Jasleen J, Ashley SW, Shimoda N, Zinner MJ, Whang EE: Glucagon-like peptide 2 stimulates intestinal epithelial proliferation in vitro. Dig Dis Sci 2002;47:1135-1140.

-34 Jasleen J, Shimoda N, Shen ER, Tavakkolizadeh A, Whang EE, Jacobs DO, Zinner MJ, Ashley SW: Signaling mechanisms of glucagon-like peptide 2-induced intestinal epithelial cell proliferation. J Surg Res 2000;90:13-18.

-35 Rocha FG, Shen KR, Jasleen J, Tavakkolizadeh A, Zinner MJ, Whang EE, Ashley SW: Glucagon-like peptide-2: Divergent signaling pathways $<$ sup $>1<$ sup $>$. J Surg Res 2004;121:5-12.

-36 Drucker DJ: Glucagon-like peptides: Regulators of cell proliferation, differentiation, and apoptosis. Mol Endocrinol 2003;17:161-171.

-37 Brubaker P, Drucker D: Structure-function of the glucagon receptor family of g protein-coupled receptors: The glucagon, gip, glp-1, and glp-2 receptors. Receptors Channels 2002;8:179-188.

-38 Fu S-P, Li S-N, Wang J-F, Li Y, Xie S-S, Xue W-J, Liu H-M, Huang B-X, Lv Q-K, Lei L-C: Bhba suppresses lpsinduced inflammation in bv-2 cells by inhibiting nf-кb activation. Mediators Inflamm 2014;2014

39 Ghosh S, Hayden MS: New regulators of nf- $\kappa b$ in inflammation. Nat Rev Immunol 2008;8:837-848.

40 Hayden MS, Ghosh S: Shared principles in nf-кb signaling. Cell 2008;132:344-362.

41 Perkins ND: Integrating cell-signalling pathways with nf-kb and ikk function. Nat Rev Mol Cell Biol 2007;8:49-62.

42 Huang P, Han J, Hui L: Mapk signaling in inflammation-associated cancer development. Protein Cell 2010;1:218-226.

43 de Heuvel E, Wallace L, Sharkey KA, Sigalet DL: Glucagon-like peptide 2 induces vasoactive intestinal polypeptide expression in enteric neurons via phophatidylinositol 3-kinase-gamma signaling. Am J Physiol Endocrinol Metab 2012;303:E994-1005. 


\begin{tabular}{|c|c|c|}
\hline Cellular Physiolory & Cell Physiol Biochem 2014;34:590-602 & \\
\hline and Biochemistry & $\begin{array}{l}\text { DOI: } 10.1159 / 000363025 \\
\text { Publisned online: August } 11,2014\end{array}$ & $\begin{array}{l}\text { (O) } 2014 \text { S. Karger AG, Basel } \\
\text { www.karger.com/cpb }\end{array}$ \\
\hline
\end{tabular}

-44 Angelone T, Filice E, Quintieri AM, Imbrogno S, Amodio N, Pasqua T, Pellegrino D, Mule F, Cerra MC: Receptor identification and physiological characterisation of glucagon-like peptide- 2 in the rat heart. Nutr Metab Cardiovasc Dis : NMCD 2012;22:486-494.

45 Jasleen J, Shimoda N, Shen ER, Tavakkolizadeh A, Whang EE, Jacobs DO, Zinner MJ, Ashley SW: Signaling mechanisms of glucagon-like peptide 2-induced intestinal epithelial cell proliferation. J Surg Res 2000;90:13-18.

-46 Yusta B, Somwar R, Wang F, Munroe D, Grinstein S, Klip A, Drucker DJ: Identification of glucagon-like peptide-2 (glp-2)-activated signaling pathways in baby hamster kidney fibroblasts expressing the rat glp-2 receptor. J Biol Chem 1999;274:30459-30467.

47 Lawrence T, Natoli G: Transcriptional regulation of macrophage polarization: Enabling diversity with identity. Nat Rev Immunol 2011;11:750-761.

48 Gautier EL, Shay T, Miller J, Greter M, Jakubzick C, Ivanov S, Helft J, Chow A, Elpek KG, Gordonov S: Geneexpression profiles and transcriptional regulatory pathways that underlie the identity and diversity of mouse tissue macrophages. Nat Immunol 2012;13:1118-1128.

-49 Foster SL, Hargreaves DC, Medzhitov R: Gene-specific control of inflammation by tlr-induced chromatin modifications. Nature 2007;447:972-978.

50 Mikita J, Dubourdieu-Cassagno N, Deloire MS, Vekris A, Biran M, Raffard G, Brochet B, Canron M-H, Franconi J-M, Boiziau C: Altered $\mathrm{m} 1 / \mathrm{m} 2$ activation patterns of monocytes in severe relapsing experimental rat model of multiple sclerosis. Amelioration of clinical status by $\mathrm{m} 2$ activated monocyte administration. Mult Scler 2011;17:2-15. 